ORIGINAL RESEARCH PAPER

\title{
ANTIOXIDANT AND PHENOLIC CONSTITUENTS OF HYPOXIS COLCHICIFOLIA
}

\author{
SUGGESSAN MOODLEY ${ }^{1}$, DEPIKA DWARKA ${ }^{1}$, HIMANSU BAIJNATH $^{2}$, JOHN MELLEM $^{1 *}$
}

\author{
${ }^{I}$ Durban University of Technology, Department of Biotechnology and Food Technology, \\ Durban, KwaZulu-Natal, South Africa \\ ${ }^{2}$ University of KwaZulu-Natal, School of Biological Sciences, Durban, South Africa. \\ *corresponding author: johnm@dut.ac.za
}

Received on 25 May 2020

Revised on 1 September 2020

\begin{abstract}
Hypoxis colchicifolia is extensively used in traditional medicine in Southern Africa. Providing a rationale and indicating the toxicity of the plant is essential for its future use as a natural therapeutic agent. In this study $H$. colchicifolia corm and leaf extracts were qualitatively assessed for phytochemical constituents and total phenolic content. The antioxidant potential of the extracts was evaluated using the 1,1-Diphenyl-2picryl-hydrazyl assay, 2,2'-azinobis-(3-ethylbenzothiazolline)-6-sulfonic acid assay, phosphomolybdenum assay, cupric ion reducing capacity assay and the ferric reducing antioxidant power assay. All extracts indicated the presence of key phytochemical constituents and no toxicity. The extracts showed good antioxidant potential against various free radicals. Most extracts exhibited a lower $\mathrm{IC}_{50}$ than that of the positive control (rutin) against free radicals, thus indicating the good antioxidant potential of the extracts. The extracts of leaves and corms cannot be used interchangeably due to differences in the phytochemical composition. Acetone and methanol extracts show the most favorable results demonstrating the solvents' effectiveness in the phytochemical extraction of $H$. colchicifolia. The study also sheds light on the use of $H$. colchicifolia leaves as a natural alternative, which has not been previously explored. The $H$. colchicifolia extracts exhibit promising antioxidant potential, validating their use as a tonic for good health.
\end{abstract}

Keywords: Hypoxis colchicifolia, antioxidant, phytochemical, African potato

\section{Introduction}

Antioxidants are nature's way of defending cells against attack by reactive oxygen species (ROS). When the free radicals in the body outnumber the antioxidant defenses, this state is referred to as oxidative stress (Shahidi and Ambigaipalan, 2015). Oxidative stress causes serious cell damage, leading to a variety of human

https://doi.org/10.35219/foodtechnology.2020.2.01 
diseases like Alzheimer's, Parkinson's, atherosclerosis, cancer, arthritis, immunological incompetence and neurodegenerative disorder (Surveswaran et al., 2007, Pandey and Rizvi, 2009). The body naturally circulates a variety of nutrients for their antioxidant properties and manufactures antioxidant enzymes in order to control these destructive chain reactions (Hässig et al., 1999).

Vitamin C, vitamin E, carotenes and lipoic acid are well known and well researched antioxidants. Most of these antioxidants are found in the foods and beverages that we consume and improve our health as well as wellbeing.

Secondary plant metabolites are usually classified by their biosynthetic pathways. Phenolics, terpenoids and alkaloids are the three large molecule families considered, with glycosides, saponins, as well as tannins being part of them, according to their specific structure (Bourgaud et al., 2001). Biological studies of secondary metabolites have revealed a broad spectrum of physiological and pharmacological properties. The antioxidant potential of a plant extract is due to the various free radical scavenging molecules present (Choi et al., 2002), with each phytochemical constituent in the extract having certain biological activities due to their chemical structure (Tiwari et al., 2011).

Hypoxis colchicifolia is commonly referred to as broad leaved Hypoxis, 'inkomfe', 'igudu', 'ingcobo' and 'ilabatheka', in Zulu, both in coastal and inland regions, such as the Eastern Cape, KwaZulu-Natal, as well as the Free State. Hypoxis colchicifolia is a robust plant, relatively taller than other Hypoxis species, about 250-500 $\mathrm{mm}$ in height and growing singly, almost glabrous, unlike other Hypoxis species (Singh, 2007, Singh, 2006). It is one of the four most sought after plant species in traditional medicine (Ncube et al., 2013). Hypoxis colchicifolia corms have a few known constituents such as Haemanthine, hypoxoside and its aglycone rooperol (Chavan et al., 2013; Amusan et al., 2005). The phytochemical identification has not been carried out on the leaves and flowers, as most studies have focused on the corms, due to their extensive use in traditional medicine. The leaves are not used traditionally, though; they may contain important phytochemical constituents that are beneficial to human health. Therefore, the aim of this study was to compare the phytochemical composition, toxicity, and antioxidant potential of $H$. colchicifolia corm and leaf extracts. In vitro antioxidant assays can only classify antioxidants for their particular reaction mechanism; therefore, the use of multiple antioxidant assays is necessary in antioxidant screening.

\section{Materials and methods}

\section{Collection of plant material}

Hypoxis colchicifolia was collected and identified using taxonomic keys by Professor H. Baijnath from the School of Life Science, University of KwaZuluNatal (UKZN). The sampling site was located in Mooiriver, KwaZulu-Natal, South Africa. A voucher specimen of the authenticated plant material was deposited at 
the Ward Herbarium at UKZN (Westville campus) (Voucher number- Baijnathsn01).

\section{Preparation of plant material}

\section{Fresh corm}

Corms of Hypoxis colchicifolia were washed, dried, peeled and grated. The grated corms were ground to a pulp using a mortar and pestle. The fresh corm $(150 \mathrm{~g})$ pulp was mixed with different solvents (acetone, methanol, distilled water) in the $1: 4 \mathrm{w} / \mathrm{v}$ ratio. This was stirred for $48 \mathrm{~h}$ on a rotary shaker then samples were filtered using Whatman No. 1 filter paper. The solvents were then evaporated using a Bauchi Rotary evaporator, the remaining extract air being dried further.

\section{Dried samples}

The dried corms were peeled, grated and allowed to dry completely. The dried corms were coarsely ground in an industrial grinder (Retsch Gmbh, West Germany), then stored in labelled Schott bottles in a cool dark place until further use. The leaves were thoroughly washed and dried completely. The dried leaves were then ground. The milled sample was stored in an airtight bottle until further use. The milled corms $(20 \mathrm{~g})$ and leaves $(20 \mathrm{~g})$ were extracted in a 1:20 ratio using acetone, methanol and distilled water. The samples were allowed to shake at 200 $\mathrm{rpm}$ for $48 \mathrm{~h}$ on a rotary shaker, and subsequently filtered. The solvents from the respective filtrates were evaporated using a rotary evaporator to concentrate the extract.

\section{Phytochemical screening}

The phytochemical screening was conducted using standard qualitative methods by Tiwari et al. (2011) with minor modifications.

Test for alkaloids: The extracts were treated with Dragendroff's reagent, and the formation of a red precipitate indicated the presence of alkaloids.

Test for saponins: Five mililiters of the extract was shaken vigorously and observed for a stable persistent froth, three drops of olive oil were added and shaken vigorously, after which the formation of an emulsion was observed.

Test for tannins: $10 \mathrm{~mL}$ of aqueous solution of extracts were boiled and filtered. A few drops of $0.1 \%$ ferric chloride were added and observed for a blue-black or brownish green colouration.

Ferric chloride test: the extracts were treated with 3-4 drops of ferric chloride solution. The formation of a blue-black color indicated the presence of phenols.

Test for terpenoids: The extracts were suspended in chloroform and concentrated sulphuric acid was carefully added to form a layer. A reddish-brown color at the interface indicated the presence of terpenoids.

Test for cardiac glycosides: An aqueous solution of extracts was added to $2 \mathrm{~mL}$ of glacial acetic acid containing one drop of ferric chloride solution. This was underplayed with $1 \mathrm{~mL}$ of concentrated sulphuric acid. The formation of a brown ring indicated the presence of glycosides. 
Test for reducing sugars: The extracts were boiled with Benedict's reagent, an orange- red precipitate indicated the presence of reducing sugars.

\section{Brine shrimp lethality assay}

The safety of the extracts was tested using the Brine Shrimp lethality Assay method by Meyer et al. (1982), with minor modifications. Artificial seawater was obtained by adding $23 \mathrm{~g} \mathrm{NaCl}, 11 \mathrm{~g} \mathrm{MgCl}_{3} 6 \mathrm{H}_{2} \mathrm{O}, 4 \mathrm{~g} \mathrm{Na}_{2} \mathrm{SO}_{4}, 1.3 \mathrm{~g} \mathrm{CaCl}_{2} .2 \mathrm{H}_{2} \mathrm{O}$ and $0.7 \mathrm{~g} \mathrm{KCl}$ to distilled water, which was brought to $1 \mathrm{~L}$ with the $\mathrm{pH}$ adjusted to 9 using $0.1 \mathrm{M} \mathrm{Na}_{2} \mathrm{CO}_{3}$ solution. The extracts were re-suspended in $2 \% \mathrm{DMSO}$, in artificial seawater. The samples were prepared in $1 \mathrm{mg} / \mathrm{mL}$ and $10 \mathrm{mg} / \mathrm{mL}$ concentrations. Brine shrimp were hatched in artificial seawater over a period of 48 $\mathrm{h}$ by adding $100 \mathrm{mg}$ brine shrimp eggs to $100 \mathrm{~mL}$ artificial seawater. The incubation took place at room temperature.

The assay was conducted by adding 10 brine shrimp nauplli into $4.9 \mathrm{~mL}$ artificial seawater and $100 \mu \mathrm{L}$ sample in a 6-well plate. Potassium chromate (in the same concentration as the sample) was used as a positive control, and the artificial seawater instead of the sample was used as the negative control.

\section{Total phenol content}

The total phenolic content was determined by the method by Ainsworth and Gillespie (2007) with minor modifications. Folin Ciocalteu reagent $(10 \%, 2.5 \mathrm{~mL})$ was added to $500 \mu \mathrm{L}$ of sample $(1 \mathrm{mg} / \mathrm{mL})$, and subsequently $2 \mathrm{~mL}$ of $2 \% \mathrm{Na}_{2} \mathrm{CO}_{3}$ was also added. The reaction was then incubated at $45^{\circ} \mathrm{C}$ for $15 \mathrm{~min}$. Thereafter, the absorbance was found to be $765 \mathrm{~nm}$. A gallic acid standard curve using 100-1000 $\mu \mathrm{g} / \mathrm{mL}$ concentrations of gallic acid was used with the results expressed as milligram of gallic acid equivalents (mg GAE per $\mathrm{g}$ ).

\section{Antioxidant activity}

\section{1,1-Diphenyl-2-picryl-hydrazyl (DPPH) assay}

The DPPH assay was performed according to the method by Oboh (2006) with minor modifications. DPPH $(0.1 \mathrm{mM}, 1 \mathrm{~mL})$ was prepared in methanol and then added to $1 \mathrm{~mL}$ of the samples $(200,400,600,800$ and $1000 \mu \mathrm{g} / \mathrm{mL})$. The reaction mix was kept in the dark for $30 \mathrm{~min}$, and finally the absorbance was found to be $517 \mathrm{~nm}$. Rutin $(1 \mathrm{mg} / \mathrm{mL})$ was used as a positive control, and methanol was used as a negative control.

$$
\text { Inhibition }(\%)=\frac{A \text { sorbance }(\text { control })-A \text { bsorbance }(\text { sample })}{A b \text { sorbance }(\text { control })} \times 100
$$

\section{2,2'-azinobis(3-ethylbenzothiazolline)-6-sulfonic acid (ABTS) assay}

The ABTS' free radical scavenging ability was determined according to the method by Re et al. (1999) with minor modifications. Briefly, the ABTS solution was prepared by mixing equal parts of $7 \mathrm{mM}$ ABTS and $2.45 \mathrm{mM}$ Potassium persulphate for $16 \mathrm{~h}$. The absorbance of this solution was measured at $734 \mathrm{~nm}$. The solution was then diluted to a concentration that yielded an absorbance of 0.7 $( \pm 0.02)$ at $735 \mathrm{~nm}$. Diluted ABTS $(3 \mathrm{~mL})$ solution was added to $1 \mathrm{~mL}$ of the sample $(200,400,600,800,1000 \mu \mathrm{g} / \mathrm{mL})$. The samples were read at $734 \mathrm{~nm}$ after 5 
minutes of incubation. Rutin $(1 \mathrm{mg} / \mathrm{mL})$ was used as a positive control and methanol was used as a negative control.

$$
\text { Percentages cavenging }=\frac{A b \text { sorbance }(\text { control })-A \text { bsorbance }(\text { sample })}{A \text { sorbance }(\text { control })} \times 100
$$

\section{Phosphomolybdenum (PM) assay}

The PM assay was conducted using the method by Sudha et al. (2011) with minor modifications. A molybdate solution was prepared by adding $1 \mathrm{~mL}$ each of $0.6 \mathrm{M}$ sulphuric acid, $28 \mathrm{mM}$ sodium phosphate and $4 \mathrm{mM}$ ammonium molybdate to 20 $\mathrm{mL}$ of distilled water. The final volume was $50 \mathrm{~mL}$. Molybdate solution $(1 \mathrm{~mL})$ was added to $1 \mathrm{~mL}$ of sample $(200,400,600,800,1000 \mu \mathrm{g} / \mathrm{mL})$. This was then incubated at $95^{\circ} \mathrm{C}$ for $90 \mathrm{~min}$. The samples were cooled and showed values of 695 $\mathrm{nm}$. Rutin $(1 \mathrm{mg} / \mathrm{mL})$ was used as a positive control, and methanol was used as a negative control.

$$
\text { Inhibition }(\%)=[\text { Absorbancs }(\text { sample })-A \text { bsorbance }(\text { control })] \times 100
$$

Cupric ion reducing antioxidant capacity (Cuprac) assay

The Cuprac assay was performed according to the method devised by Phatak and Hendre (2014). Briefly, $1 \mathrm{mg}$ of $10 \mathrm{mM}$ cupric chloride, $7.5 \mathrm{mM}$ neocuprine (made in methanol), $1 \mathrm{mM}$ ammonium acetate buffer $(\mathrm{pH} 7)$ and $2 \mathrm{~mL}$ of distilled water were added to $100 \mu \mathrm{L}$ of sample $(200,400,600,800,1000 \mu \mathrm{g} / \mathrm{mL})$. The samples were incubated at room temperature for $30 \mathrm{~min}$ and the absorbance was $450 \mathrm{~nm}$. Rutin $(1 \mathrm{mg} / \mathrm{mL})$ was used as a positive control, and methanol was used as a negative control.

Ferric Reducing Antioxidant Power (FRAP) assay

The FRAP assay was conducted according to the method by Benzie and Strain (1996) with minor modifications. A $300 \mathrm{mM}$ acetate buffer was prepared by adding $3.1 \mathrm{~g}$ sodium acetate trihydrate to $16 \mathrm{~mL}$ glacial acetic acid. The $\mathrm{pH}$ was adjusted to 3.6 and the final volume was brought to $1 \mathrm{~L}$ with distilled water. Freshly prepared $10 \mathrm{mM}$ TPTZ (2, 4, 6-tripyridyl-s- triazine) in $40 \mathrm{mM} \mathrm{HCL}$ and $20 \mathrm{mM}$ $\mathrm{FeCl}_{3} \cdot 6 \mathrm{H}_{2} \mathrm{O}$ in distilled water were made. The TPTZ reagent was prepared by adding 10 parts of acetate buffer to 1 part each of TPTZ and $\mathrm{FeCl}_{3}$ solution to make up the FRAP reagent. The FRAP reagent $(3 \mathrm{~mL})$ was added to $100 \mu \mathrm{L}$ of the samples $(200,400,600,800,1000 \mu \mathrm{g} / \mathrm{mL})$. The samples were read at $593 \mathrm{~nm}$, incubated at $37^{\circ} \mathrm{C}$ and read again after 4 minutes. Ascorbic acid was used as the standard and the FRAP value for Ascorbic acid was 2.

$$
F R A P=\frac{\Delta A \text { bsorbance }{ }_{593}(\text { sample })}{\Delta A \text { bsorbance }{ }_{593}(\text { standard })} \times \text { Frapvalue of thestandard }
$$

\section{Statistical analysis}

The results were analyzed by ANOVA (Graph Pad Prism software, San Diego, CA, USA). All analysis was done in triplicate; the mean \pm standard deviation was 
calculated. $\mathrm{IC}_{50}$ was also calculated using Graph Pad Prism. The lower the $\mathrm{IC}_{50}$ concentration, the more potent the extract as a therapeutic substance.

\section{Results and discussion}

\section{Phytochemical screening}

All $H$. colchicifolia extracts tested positive for saponins, tannins, flavonoids, terpenoids, phenols and reducing sugars (Table 1). All acetone and methanol extracts were positive for cardiac glycosides and anthraquinones. Only corm extracts were positive for alkaloids, while all leaf extracts were negative for alkaloids.

Table 1. Phytochemical constituents in $H$. colchicifolia extracts using different solvent systems.

\begin{tabular}{|c|c|c|c|c|c|c|c|c|c|}
\hline Test & FCA & FCM & FCAQ & DLA & DLM & DLAQ & DCA & DCM & DCAQ \\
\hline Alkaloids & + & + & + & - & - & - & + & + & + \\
\hline Saponins & + & + & + & + & + & + & + & + & + \\
\hline Tannins & + & + & + & + & + & + & + & + & + \\
\hline Flavonoids & + & + & + & + & + & + & + & + & + \\
\hline $\begin{array}{l}\text { Cardiac } \\
\text { glycosides }\end{array}$ & + & + & - & + & + & - & + & + & - \\
\hline Terpenoids & + & + & + & + & + & + & + & + & + \\
\hline Anthraquinones & + & + & - & + & + & - & + & + & - \\
\hline Phenols & + & + & + & + & + & + & + & + & + \\
\hline Reducing sugars & + & + & + & + & + & + & + & + & + \\
\hline
\end{tabular}

Fresh corm acetone extract (FCA), fresh corm methanol extract (FCM), fresh corm aqueous extract (FCAQ), dried leaf acetone extract (DLA), dried leaf methanol extract (DLM), dried leaf aqueous extract (DLAQ), dried corm acetone extract (DCA), dried corm methanol extract (DCM), dried corm aqueous extract (DCAQ). The values represent the mean of replicate reading $(n=3)$.

In a study by Zimudzi (2014), crude methanolic extracts of Hypoxis hemerocallidea, Hypoxis obtusa, Hypoxis rigidula and Hypoxis galpinri tested positive for reducing sugars, tannins, cardiac glycosides, saponins and terpenoids; and negative for flavonoids, alkaloids and anthraquinones. The Hypoxis colchicifolia corm and leaf extracts in our study tested positive for all the phytochemical constituents tested, the only exception being the absence of alkaloids in the leaves. The phytochemical constituents identified in the study have some association with biological activities attributed to plant chemistry. Tannins possess antinociceptive, antioxidant and anti-inflammatory properties; terpenoids have anti-inflammatory and anti-microbial properties. Saponins possess anticancer, anti-diabetic, anti-inflammatory, anti-microbial and antioxidant properties; cardiac glycosides are considered to be important in treating heart conditions (Tiwari et al., 2011). 
The assessment of the aerial and subterranean parts of Hypoxis by Katerere and Eloff (2008) show a clear difference between the biological activity and the chemistry of these parts. Hypoxis hemerocallidea corms and leaves tested for chemical composition on TLC found them to be distinctly different, with leaf samples being more complex than corms. There were no apparent differences in the chemical composition of the ethanol and acetone extracts of either corms or leaves in the study by (Katerere, 2013, Katerere and Eloff, 2008).

\section{Brine shrimp lethality assay}

All $H$. colchicifolia extracts tested at different concentrations showed no mortality of the brine shrimp, indicating the non-toxic effect that extracts possess (Table 2). Potassium chromate used as the positive control was lethal from the lowest concentration tested.

Table 1. Brine shrimp lethality assay, Percentage death by $H$. colchicifolia extracts by different solvent systems.

\begin{tabular}{ccccccccccc}
\hline $\begin{array}{c}\text { Concentration } \\
(\boldsymbol{\mu g} / \mathbf{m L})\end{array}$ & $\begin{array}{c}\text { FC } \\
\mathbf{A}\end{array}$ & $\begin{array}{c}\text { FC } \\
\mathbf{M}\end{array}$ & $\begin{array}{c}\text { FCA } \\
\mathbf{Q}\end{array}$ & $\begin{array}{c}\text { DL } \\
\mathbf{A}\end{array}$ & $\begin{array}{c}\text { DL } \\
\mathbf{M}\end{array}$ & $\begin{array}{c}\text { DL } \\
\text { AQ }\end{array}$ & $\begin{array}{c}\text { DC } \\
\text { A }\end{array}$ & $\begin{array}{c}\text { DC } \\
\text { M }\end{array}$ & $\begin{array}{c}\text { DC } \\
\text { AQ }\end{array}$ & $\begin{array}{c}\text { Positive } \\
\text { control }\end{array}$ \\
\hline $\mathbf{0}$ & 0 & 0 & 0 & 0 & 0 & 0 & 0 & 0 & 0 & 0 \\
$\mathbf{1 0 0}$ & 0 & 0 & 0 & 0 & 0 & 0 & 0 & 0 & 0 & 100 \\
$\mathbf{1 0 0 0}$ & 0 & 0 & 0 & 0 & 0 & 0 & 0 & 0 & 0 & 100 \\
$\mathbf{1 0 0 0 0}$ & 0 & 0 & 0 & 0 & 0 & 0 & 0 & 0 & 0 & 100 \\
$\mathbf{1 0 0 0 0 0}$ & 0 & 0 & 0 & 0 & 0 & 0 & 0 & 0 & 0 & 100 \\
\hline
\end{tabular}

Fresh corm acetone extract (FCA), fresh corm methanol extract (FCM), fresh corm aqueous extract (FCAQ), dried leaf acetone extract (DLA), dried leaf methanol extract (DLM), dried leaf aqueous extract (DLAQ), dried corm acetone extract (DCA), dried corm methanol extract (DCM), dried corm aqueous extract (DCAQ). The values represent the mean of replicate reading $(n=3)$.

Jooste (2012) showed that the corms of $H$. hemerocallidea showed cytotoxicity on brine shrimp lethality at 10,100 and $1000 \mu \mathrm{g} / \mathrm{mL}$ (Jooste, 2012). However, Ramulondi et al. (2018) found that an aqueous extract of $H$. hemerocallidea corms had a low brine shrimp lethality assay mortality percentage of 4 and 5\% after 24 and $48 \mathrm{~h}$ respectively. The organic solvent extract had a higher mortality, of 29 and $54 \%$ mortality after 24 and $48 \mathrm{~h}$ respectively. A study by Zimudzi (2014) revealed that the extracts of Hypoxis corms are nontoxic to brine shrimp nauplli. In this study, all the extracts tested were nontoxic, their highest concentration being $100000 \mu \mathrm{g} / \mathrm{mL}$.

\section{Total phenol content}

The methanol extract of dried corms of $H$. colchicifolia has the highest phenolic content out of all the extracts evaluated $(204.80 \pm 1.73 \mathrm{mg} / \mathrm{g})$; the aqueous extract of dried leaves has the lowest phenolic content $(103.67 \pm 1.15 \mathrm{mg} / \mathrm{g})$. The statistical analysis of the results showed no significant difference between FCA and FCM, 
FCAQ and DCM, DLA and DLM; nor between DCA and DCAQ (Table 3). The remaining extracts showed significant differences $p<0.0001$.

Table 2. Total phenolic content of $H$. colchicifolia extracts by different solvent systems.

\begin{tabular}{ccc}
\hline Sample & Solvent type & GAE (gallic acid equivalent) $\mathbf{~ m g / g}$ \\
\hline \multirow{3}{*}{ Fresh Corms } & Acetone & $186.53 \pm 5.08^{\mathrm{c}}$ \\
& Methanol & $186.87 \pm 0.81^{\mathrm{c}}$ \\
& Aqueous & $198.53 \pm 1.89^{\mathrm{a}}$ \\
\hline \multirow{3}{*}{ Dried Leaves } & Acetone & $112.80 \pm 0.33^{\mathrm{g}}$ \\
& Methanol & $115.13 \pm 3.45^{\mathrm{g}}$ \\
& Aqueous & $103.67 \pm 1.15^{\mathrm{i}}$ \\
\hline \multirow{3}{*}{ Dried Corms } & Acetone & $157.47 \pm 2.05^{\mathrm{e}}$ \\
& Methanol & $204.80 \pm 1.73^{\mathrm{a}}$ \\
& Aqueous & $160.60 \pm 1.23^{\mathrm{e}}$ \\
\hline
\end{tabular}

The data represent the mean \pm standard deviation $(n=3)$. Superscript letters indicate significant difference $(p<0.0001)$.

The total phenolic content of the three fresh corm extracts was similar and showed no significant difference. The total phenolic content of the leaf extracts was lower $( \pm 50 \%)$ than that of the fresh and dried corm extracts. The aqueous extract of dried leaves had the lowest phenolic content. In a study by Laher et al. (2013), the total phenolic content of fresh $H$. hemerocallidea corms and leaves had a significantly higher total phenolic content than that of dried corms and leaves. Phenolic compounds are considered responsible for antioxidant activity and effective free radical scavenging; hence, the quantity of total phenols present gives an indication of the samplesț antioxidant ability. Fresh corms had a total phenolic content of $173.59 \mathrm{mgGAE} / \mathrm{g}$. Fresh $H$. hemerocallidea leaves had a higher flavonoid content than that of dried leaves. An assessment of 7 Hypoxis species for the total phenolic content by (Nsibande et al., 2018) found the total phenolic content ranging from 134.79 to $396 \mu \mathrm{g} / \mathrm{g}$ in the corm extracts of the Hypoxis species evaluated. In the study $H$. hemerocallidea had a total phenolic content of $204.56 \mu \mathrm{g} / \mathrm{g}$, thus keeping in line with the findings of this study.

\section{Antioxidant activity}

\section{1,1-Diphenyl-2-picryl-hydrazyl (DPPH) assay}

The acetone extract of the dried corms of $H$. colchicifolia shows the highest DPPH free radical inhibition potential, and the fresh corm aqueous extract shows the poorest inhibition potential (Figure 1). The $\mathrm{IC}_{50}$ for DPPH in descending order are as follows: fresh corm aqueous $(23.16 \mu \mathrm{g} / \mathrm{mL})$, fresh corm methanol $(21.25$ $\mu \mathrm{g} / \mathrm{mL})$, dried corm aqueous $(20.16 \mu \mathrm{g} / \mathrm{mL})$, dried corm methanol $(18.91 \mu \mathrm{g} / \mathrm{mL})$, dried leaf aqueous $(18.76 \mu \mathrm{g} / \mathrm{mL})$, fresh corm acetone $(18.72 \mu \mathrm{g} / \mathrm{mL})$, dried leaf methanol $(18.44 \mu \mathrm{g} / \mathrm{mL})$, dried leaf acetone $(17.89 \mu \mathrm{g} / \mathrm{mL})$ and dried corm acetone $(17.56 \mu \mathrm{g} / \mathrm{mL})$. The $\mathrm{IC}_{50}$ of the positive control rutin was $21.79 \mu \mathrm{g} / \mathrm{mL}$. There was no significant difference in the results of DLA and DLM, DLA and DLAQ; and DLM and DLAQ. So, it can be concluded that there was no significant difference 
between all leaf extracts. The fresh and dried corm extracts had significant differences $(p<0.0001)$ between each other, as well as between the leaf extracts and the positive control.

A

$\square$ Acetone Methanol $\square$ Aqueous

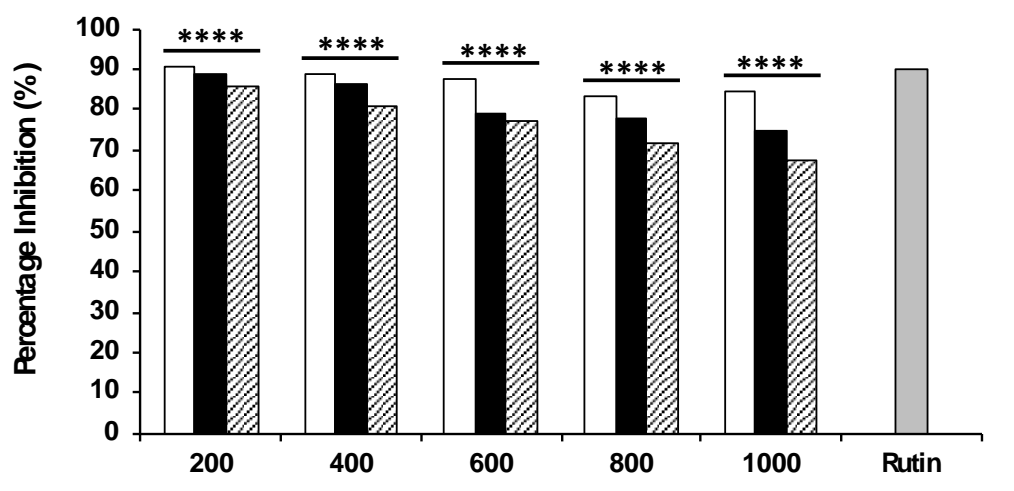

B

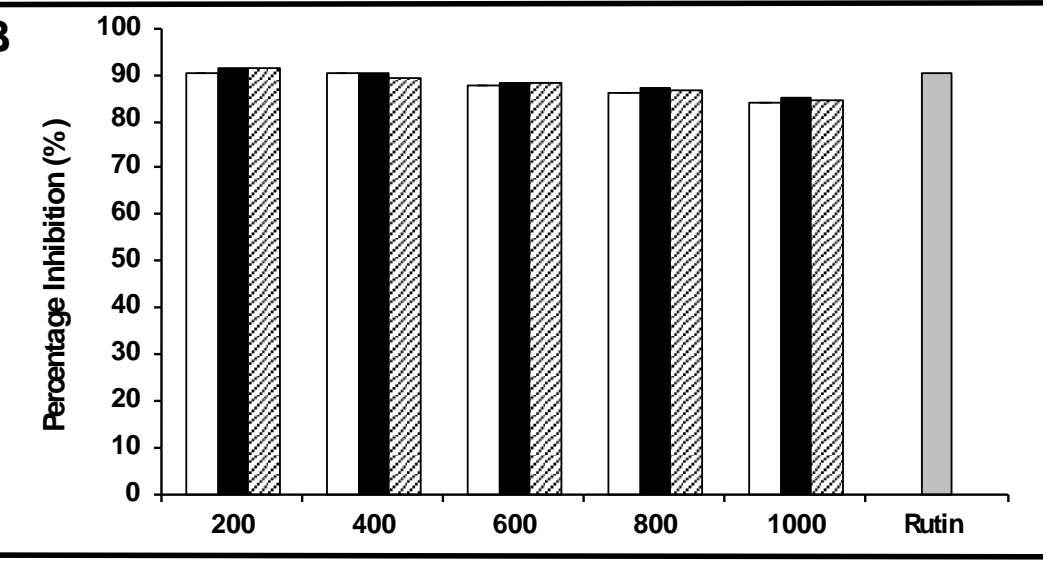

C

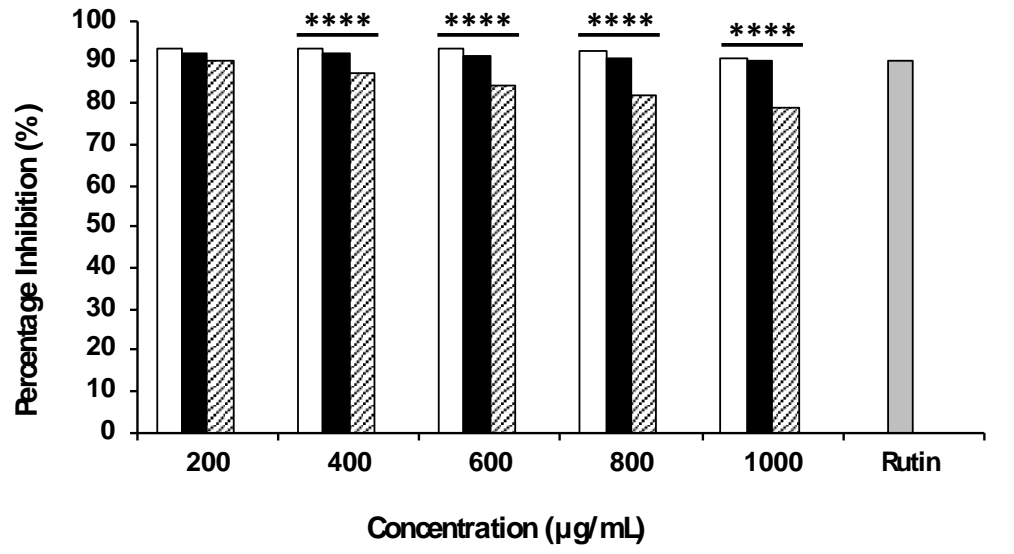

Figure 1. DPPH Inhibition by $H$. colchicifolia extracts [A - Solvent extracts of fresh corms; B - solvent extracts of dried leaves; C - solvent extracts of dried corms]. The values represent the mean \pm standard deviation of replicate reading $(n=3)$ (**** indicates significant differences $p<0.0001)$. 
However, the dried leaf extracts possessed a lower total phenolic content, but had as good a DPPH scavenging potential as the other extracts tested. The acetone extracts of the fresh corms, dried leaves, as well as dried corms had better potential than aqueous and methanol extracts. The acetone extract of dried corms had the lowest $\mathrm{IC}_{50}$ for DPPH scavenging. There was no significant difference between each of the nine extracts and the extracts as compared to rutin. A study by Laporta et al., 2007 showed that extracts of $H$. hemerocallidea have greater antioxidant activity than extracts of green tea and olive leaf (Laporta et al., 2007).

An antioxidant inhibition screening against DPPH and ABTS free radicals by (Madikizela and McGaw, 2019) found that aqueous extracts of $H$. colchicifolia corms were most effective against free radicals, with $H$. colchicifolia showing a weak DPPH scavenging potential. Acetone, ethanol, hot and cold-water extracts were evaluated, with aqueous extracts having the lowest $\mathrm{IC}_{50}$ values for antioxidant inhibition. Hot water extract of $H$. colchicifolia had an $\mathrm{IC}_{50}$ of $12.18 \mu \mathrm{g} / \mathrm{mL}$ against ABTS free radicals and the cold-water extract had an $\mathrm{IC}_{50}$ of $19.75 \mu \mathrm{g} / \mathrm{mL}$ against DPPH free radicals.

\section{2,2'-azinobis(3-ethylbenzothiazolline)-6-sulfonic acid (ABTS) assay}

The methanol extract of dried leaves exhibited the greatest inhibitory effect (Figure 2). The $\mathrm{IC}_{50}$ for ABTS inhibition in descending order are as follows: fresh corm methanol $(153 \mu \mathrm{g} / \mathrm{mL})$, fresh corm acetone $(120.1 \mu \mathrm{g} / \mathrm{mL})$, dried corm aqueous $(118.6 \mu \mathrm{g} / \mathrm{mL})$, dried corm methanol $(106.4 \mu \mathrm{g} / \mathrm{mL})$, dried corm acetone $(106.4$ $\mu \mathrm{g} / \mathrm{mL})$, fresh corm aqueous $(104.5 \mu \mathrm{g} / \mathrm{mL})$, dried leaf acetone $(89.98 \mu \mathrm{g} / \mathrm{mL})$, dried leaf aqueous $(85.57 \mu \mathrm{g} / \mathrm{mL})$ and dried leaf methanol $(74.46 \mu \mathrm{g} / \mathrm{mL})$. The $\mathrm{IC}_{50}$ for the positive control rutin was $30.69 \mu \mathrm{g} / \mathrm{mL}$. Leaf extracts were most effective against ABTS cations, with the methanol extract having the lowest $\mathrm{IC}_{50}$, followed by aqueous and acetone extract. Fresh corm extracts were the least effective in scavenging ABTS radicals. There was a significant difference between all the extracts tested, including the positive control. The assessment of Hypoxis argentea for antioxidant potential using DPPH and ABTS methods found that the ethanol and aqueous extracts of corm had high antioxidant potential, as well as an ABTS inhibition of more than $90 \%$ at a $500 \mu \mathrm{g} / \mathrm{mL}$ concentration. The extracts showed moderate DPPH scavenging potential (Akinrinde et al., 2018). These findings were similar to that of this study, as corm extracts exhibited high antioxidant potential.

\section{Phosphomolybdenum (PM) assay}

The acetone extract of dried corms of $H$. colchicifolia was shown to have the highest TEAC against phosphomolybdenum free radicals, while the aqueous extract of fresh corms exhibited the lowest potential (Table 4). All acetone extracts had a higher potential than that of rutin $(150.53 \pm 1.76 \mu \mathrm{g} / \mathrm{mL})$. The acetone extract of dried corms inhibited PM free radicals better than other extracts, and had the highest trolox equivalent. There was a significant difference $(p<0.0001)$ between all the extracts tested, including the positive control. 
A
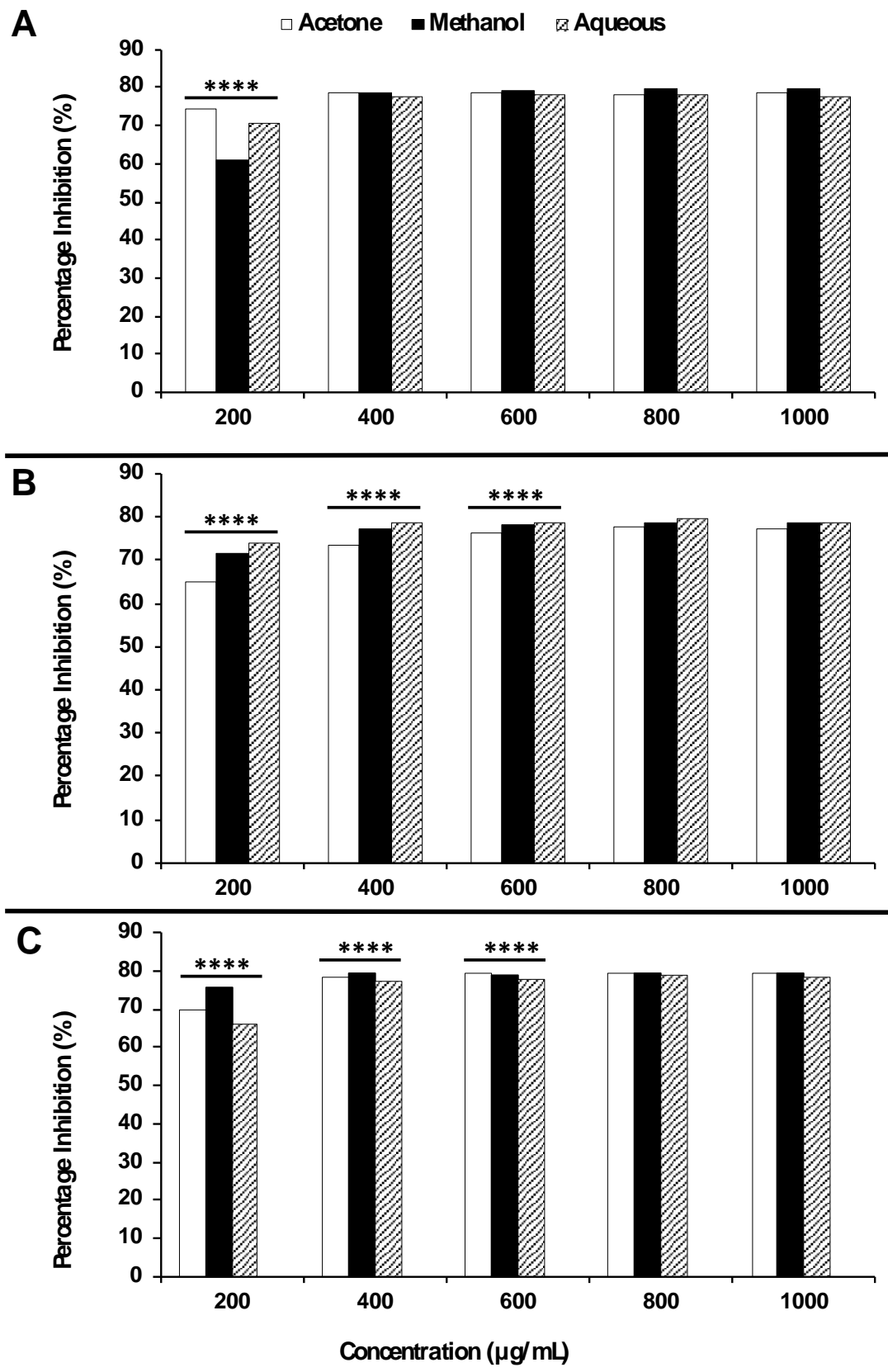

Figure 2. ABTS Inhibition by H. colchicifolia extracts [A - Solvent extracts of fresh corms; B - solvent extracts of dried leaves; C - solvent extracts of dried corms]. The values represent the mean \pm standard deviation of replicate reading $(n=3)(* * * *$ indicates significant differences $p<0.0001$ ). 
Table 4. Trolox equivalence antioxidant capacity (TEAC) of $H$. colchicifolia extracts against phosphomolybdenum free radicals.

\begin{tabular}{ccccc}
\hline Sample & $\begin{array}{c}\text { Concentration } \\
(\boldsymbol{\mu g} / \mathbf{m L})\end{array}$ & Acetone & Methanol & Aqueous \\
\hline \multirow{2}{*}{$\begin{array}{c}\text { Fresh corm } \\
\text { extracts }\end{array}$} & $\mathbf{2 0 0}$ & $54.30 \pm 1.32^{\mathrm{ab}}$ & $80.11 \pm 1.32^{\mathrm{bc}}$ & $68.82 \pm 0.88^{\mathrm{ac}}$ \\
& $\mathbf{4 0 0}$ & $109.14 \pm 3.07^{\mathrm{ab}}$ & $95.16 \pm 0.44^{\mathrm{b}}$ & $96.24 \pm 3.07^{\mathrm{ac}}$ \\
& $\mathbf{6 0 0}$ & $132.26 \pm 5.27^{\mathrm{ab}}$ & $113.98 \pm 0.88^{\mathrm{b}}$ & $110.22 \pm 3.07^{\mathrm{ac}}$ \\
& $\mathbf{1 0 0 0}$ & $152.69 \pm 1.76^{\mathrm{ab}}$ & $124.73 \pm 0.88^{\mathrm{bc}}$ & $103.76 \pm 3.07^{\mathrm{ac}}$ \\
& $\mathbf{0}$ & $178.49 \pm 7.90^{\mathrm{ab}}$ & $130.11 \pm 3.51^{\mathrm{bc}}$ & $106.45 \pm 4.39^{\mathrm{ac}}$ \\
\hline Dried leaf & $\mathbf{2 0 0}$ & $74.73 \pm 3.07^{\mathrm{a}}$ & $72.94 \pm 2.92^{\mathrm{a}}$ & $65.05 \pm 1.32^{\mathrm{bc}}$ \\
extracts & $\mathbf{4 0 0}$ & $117.74 \pm 7.46^{\mathrm{ab}}$ & $76.88 \pm 0.44^{\mathrm{a}}$ & $82.80 \pm 4.39^{\mathrm{bc}}$ \\
& $\mathbf{6 0 0}$ & $151.61 \pm 2.63^{\mathrm{ab}}$ & $104.30 \pm 2.63^{\mathrm{ac}}$ & $67.20 \pm 2.19^{\mathrm{bc}}$ \\
& $\mathbf{8 0 0}$ & $162.90 \pm 4.83^{\mathrm{ab}}$ & $106.45 \pm 2.63^{\mathrm{a}}$ & $105.91 \pm 1.32^{\mathrm{bc}}$ \\
& $\mathbf{1 0 0 0}$ & $162.37 \pm 0.88^{\mathrm{ab}}$ & $147.85 \pm 2.19^{\mathrm{ac}}$ & $116.67 \pm 4.83^{\mathrm{bc}}$ \\
\hline & $\mathbf{0}$ & 0 & 0 & 0 \\
\hline Dried corm & $\mathbf{2 0 0}$ & $107.53 \pm 3.51^{\mathrm{ac}}$ & $63.44 \pm 0.88^{\mathrm{b}}$ & $58.60 \pm 0.44^{\mathrm{ac}}$ \\
& $\mathbf{4 0 0}$ & $127.96 \pm 0.00^{\mathrm{ac}}$ & $70.43 \pm 1.32^{\mathrm{b}}$ & $66.13 \pm 0.44^{\mathrm{ac}}$ \\
& $\mathbf{6 0 0}$ & $143.01 \pm 1.76^{\mathrm{ac}}$ & $81.18 \pm 1.32^{\mathrm{b}}$ & $84.41 \pm 1.32^{\mathrm{ac}}$ \\
& $\mathbf{8 0 0}$ & $160.22 \pm 0.88^{\mathrm{ac}}$ & $88.71 \pm 0.44^{\mathrm{b}}$ & $91.94 \pm 1.32^{\mathrm{ac}}$ \\
& $\mathbf{1 0 0 0}$ & $180.65 \pm 2.63^{\mathrm{ac}}$ & $131.72 \pm 0.44^{\mathrm{bc}}$ & $120.43 \pm 6.15^{\mathrm{ac}}$ \\
\hline
\end{tabular}

The values represent the mean \pm standard deviation of replicate reading $(n=3)$. Superscript letters indicate significant difference $(p<0.0001)$.

\section{Cupric ion reducing antioxidant capacity (Cuprac) assay}

All extracts had a poor TEAC as compared to that of rutin $(978.79 \pm 3.89 \mu \mathrm{g} / \mathrm{mL})$; however, the methanol extract of fresh corms of $H$. colchicifolia had the highest TEAC against cupric ion free radicals, while the methanol extract of dried leaves had the lowest TEAC potential (Table 5). There was no significant difference between FCA and FCM, DLM and DCM; nor between DCM and DCAQ.

The remaining extracts tested had a significant difference $(p<0.0001)$ when compared to each other and the positive control. In a study by Güçlü et al. (2006) on methanol extracts of dry and fresh apricots, it was shown that TEAC against cupric ion free radicals ranged between 2.67 and $52.47 \mu \mathrm{mol} / \mathrm{g}$. The methanol extracts of 21 Macedonian medicinal plants tested against cupric ion free radicals by Tusevski et al. (2014) had results ranging from 52.89 to $1068.58 \mu \mathrm{mol} / \mathrm{g}$, TEAC with Origanum vulgare having the highest equivalent. A study by Zengin et al. (2015) on solvent extracts of three medicinal plants (Hedysarum varium, Onbrychis hypargyea and Vicia truncatula) showed $\mathrm{EC}_{50}$ values ranging between 
0.69 and $3.01(\mathrm{mg} / \mathrm{mL})$, with Hedysarum varium having the best cupric potential in the study.

Table 5. Trolox equivalence antioxidant capacity (TEAC) of $H$. colchicifolia extracts against cupric ion free radicals.

\begin{tabular}{|c|c|c|c|c|}
\hline Sample & $\begin{array}{c}\text { Concentration } \\
(\mu \mathrm{g} / \mathrm{mL})\end{array}$ & Acetone & Methanol & Aqueous \\
\hline \multirow{6}{*}{$\begin{array}{l}\text { Fresh corm } \\
\text { extracts }\end{array}$} & 0 & 0 & 0 & 0 \\
\hline & 200 & $107.78 \pm 9.79^{b}$ & $105.03 \pm 8.92^{\mathrm{ac}}$ & $42.65 \pm 2.83^{b c}$ \\
\hline & 400 & $184.84 \pm 10.72^{\mathrm{b}}$ & $185.29 \pm 5.77^{\mathrm{ac}}$ & $99.07 \pm 2.59^{\mathrm{bc}}$ \\
\hline & 600 & $254.55 \pm 5.54^{\mathrm{b}}$ & $261.89 \pm 2.97^{\mathrm{ac}}$ & $118.79 \pm 4.05^{b c}$ \\
\hline & 800 & $325.65 \pm 1.72^{b}$ & $303.17 \pm 9.98^{\mathrm{ac}}$ & $136.68 \pm 1.95^{b c}$ \\
\hline & 1000 & $359.13 \pm 3.61^{\mathrm{b}}$ & $362.80 \pm 3.24^{\mathrm{ac}}$ & $225.66 \pm 9.08^{b c}$ \\
\hline \multirow{6}{*}{$\begin{array}{l}\text { Dried leaf } \\
\text { extracts }\end{array}$} & 0 & 0 & 0 & 0 \\
\hline & 200 & $27.97 \pm 5.15^{\mathrm{ab}}$ & $36.23 \pm 4.05^{\mathrm{a}}$ & $7.44 \pm 1.13^{\mathrm{ab}}$ \\
\hline & 400 & $70.63 \pm 2.25^{\mathrm{a}}$ & $58.24 \pm 7.37^{\mathrm{ac}}$ & $57.79 \pm 7.48^{\mathrm{ab}}$ \\
\hline & 600 & $124.29 \pm 3.89^{\mathrm{a}}$ & $90.81 \pm 3.61^{\mathrm{a}}$ & $81.18 \pm 5.54^{\mathrm{ab}}$ \\
\hline & 800 & $187.59 \pm 2.97^{\mathrm{a}}$ & $110.53 \pm 7.86^{\mathrm{ac}}$ & $118.33 \pm 8.13^{\mathrm{ab}}$ \\
\hline & 1000 & $\begin{array}{c}228.87 \pm 16.85^{\mathrm{a}} \\
\mathrm{b}\end{array}$ & $\underset{\mathrm{c}}{167.87 \pm 14.49^{\mathrm{a}}}$ & $188.05 \pm 3.24^{\mathrm{ab}}$ \\
\hline \multirow{6}{*}{$\begin{array}{l}\text { Dried corm } \\
\text { extracts }\end{array}$} & $\mathbf{0}$ & 0 & 0 & 0 \\
\hline & 200 & $49.53 \pm 7.89^{a}$ & $38.98 \pm 2.25^{b}$ & $8.25 \pm 2.83^{\mathrm{a}}$ \\
\hline & 400 & $104.11 \pm 12.01^{\mathrm{a}}$ & $66.96 \pm 7.97^{b}$ & $60.08 \pm 1.72^{\mathrm{a}}$ \\
\hline & 600 & $\underset{\mathrm{b}}{183.00 \pm 14.23^{\mathrm{a}}}$ & $95.40 \pm 6.83^{b}$ & $98.15 \pm 20.81^{\mathrm{ac}}$ \\
\hline & 800 & $\begin{array}{c}227.95 \pm 10.07^{\mathrm{a}} \\
\mathrm{b}\end{array}$ & $135.76 \pm 1.72^{\mathrm{b}}$ & $133.01 \pm 2.39^{\mathrm{ac}}$ \\
\hline & 1000 & $288.49 \pm 3.43^{\mathrm{ab}}$ & $176.12 \pm 13.96^{\mathrm{b}}$ & $\underset{\mathrm{c}}{248.13 \pm 12.15^{\mathrm{a}}}$ \\
\hline
\end{tabular}

The values represent the mean \pm standard deviation of replicate reading $(\mathrm{n}=3)$. Superscript letters indicate significant difference $(p<0.0001)$.

Ferric reducing antioxidant power (FRAP) assay

The methanol extract of $H$. colchicifolia dried corms had the highest ferric ion free radical scavenging ability, while the acetone extract of dried leaves had the lowest scavenging ability (Table 6).

There was no significant difference between the following extracts: FCA and DLA, FCA and DLM, DLA and DLM, DLM and DCA, DLM and DCAQ; and DCA and DCAQ. The rest of the extracts tested had a significant difference $(p<0.0001)$ between each other, and between each of them and the positive control. 
Table 6. Trolox equivalence antioxidant capacity (TEAC) of $H$. colchicifolia extracts against ferric ion free radicals.

\begin{tabular}{ccccc}
\hline Sample & $\begin{array}{c}\text { Concentration } \\
(\boldsymbol{\mu g} / \mathbf{m L})\end{array}$ & Acetone & Methanol & Aqueous \\
\hline Fresh corm & $\mathbf{0}$ & 0 & 0 & 0 \\
extracts & $\mathbf{2 0 0}$ & $0.46 \pm 0.02^{\mathrm{a}}$ & $0.68 \pm 0.05^{\mathrm{a}}$ & $0.31 \pm 0.10^{\mathrm{a}}$ \\
& $\mathbf{4 0 0}$ & $0.52 \pm 0.01^{\mathrm{a}}$ & $0.88 \pm 0.35^{\mathrm{a}}$ & $0.66 \pm 0.07^{\mathrm{ab}}$ \\
& $\mathbf{6 0 0}$ & $1.05 \pm 0.17^{\mathrm{a}}$ & $1.22 \pm 0.09^{\mathrm{a}}$ & $0.83 \pm 0.10^{\mathrm{a}}$ \\
& $\mathbf{8 0 0}$ & $1.30 \pm 0.16^{\mathrm{ac}}$ & $1.73 \pm 0.11^{\mathrm{a}}$ & $2.28 \pm 0.16^{\mathrm{ab}}$ \\
Dried leaf & $\mathbf{1 0 0 0}$ & $1.36 \pm 0.17^{\mathrm{ab}}$ & $2.26 \pm 0.19^{\mathrm{a}}$ & $2.49 \pm 0.17^{\mathrm{ab}}$ \\
\hline extracts & $\mathbf{0}$ & 0 & 0 & 0 \\
& $\mathbf{2 0 0}$ & $0.52 \pm 0.01^{\mathrm{a}}$ & $0.44 \pm 0.03^{\mathrm{a}}$ & $0.41 \pm 0.01^{\mathrm{a}}$ \\
& $\mathbf{6 0 0}$ & $0.64 \pm 0.02^{\mathrm{a}}$ & $0.80 \pm 0.07^{\mathrm{a}}$ & $0.63 \pm 0.01^{\mathrm{a}}$ \\
& $\mathbf{8 0 0}$ & $0.83 \pm 0.07^{\mathrm{a}}$ & $1.12 \pm 0.11^{\mathrm{ab}}$ & $1.39 \pm 0.15^{\mathrm{a}}$ \\
& $\mathbf{1 0 0 0}$ & $1.07 \pm 0.15^{\mathrm{a}}$ & $1.39 \pm 0.09^{\mathrm{ab}}$ & $1.75 \pm 0.10^{\mathrm{a}}$ \\
& $\mathbf{0}$ & $1.24 \pm 0.11^{\mathrm{a}}$ & $1.44 \pm 0.13^{\mathrm{ab}}$ & $2.00 \pm 0.04^{\mathrm{ac}}$ \\
\hline extracts & $\mathbf{2 0 0}$ & 0 & 0 & 0 \\
& $\mathbf{4 0 0}$ & $1.05 \pm 0.05^{\mathrm{a}}$ & $1.19 \pm 0.13^{\mathrm{a}}$ & $0.93 \pm 0.06^{\mathrm{a}}$ \\
& $\mathbf{6 0 0}$ & $1.32 \pm 0.35^{\mathrm{a}}$ & $1.65 \pm 0.06^{\mathrm{a}}$ & $1.06 \pm 0.05^{\mathrm{ac}}$ \\
& $\mathbf{8 0 0}$ & $1.43 \pm 0.31^{\mathrm{a}}$ & $2.05 \pm 0.11^{\mathrm{ab}}$ & $1.29 \pm 0.28^{\mathrm{ac}}$ \\
& $\mathbf{1 0 0 0}$ & $1.54 \pm 0.13^{\mathrm{a}}$ & $2.78 \pm 0.11^{\mathrm{ab}}$ & $1.38 \pm 0.19^{\mathrm{ac}}$ \\
\hline
\end{tabular}

The values represent the mean \pm standard deviation of replicate reading $(n=3)$. Superscript letters indicate significant difference $(p<0.0001)$.

In this study, the methanol extract of dried corms manifested the highest ferric ion scavenging potential, and the acetone extract of fresh corms also had a greater scavenging potential than that of rutin $(2.31 \pm 0.10 \mu \mathrm{mol} / \mathrm{mL})$. In this study, acetone extracts generally had poor potential, however there were no significant differences as compared to some of the other solvent extracts. Aqueous extracts of $H$. hemerocallidea and active compound hypoxoside were evaluated for their antioxidant potential against DPPH and FRAP free radicals by (Nair et al., 2007). Hypoxis hemerocallidea extracts showed dose dependent free radical scavenging, with hypoxoside not having any antioxidant potential when tested alone (Nair et al., 2013). No single assay can capture the different modes of action of the antioxidant.

Antioxidants work by various mechanisms; by free radical scavenging activity, donating hydrogen to radicals metal chelating activity, reducing power, quenching singlet oxygen, and inhibition of $\beta$-carotene (Badarinath et al., 2010). 


\section{Conclusions}

The composition of Hypoxis colchicifolia corm and leaf extracts was shown to be phytochemically different, the solvent used for extraction being the determining factor. Only the acetone and methanol extracts were shown to have a full spectrum of phytochemical constituents. The plant is shown to be nontoxic and safe to use, with extracts exhibiting promising antioxidant potential; the acetone and methanol corm extracts yielded the most favourable results. This could be the reason why only the corms are used in traditional medicine. The leaf extracts have moderate phenolic content and may have promising biological activity, even though their antioxidant ability is limited. Further studies are recommended to assess the quantitative phytochemical composition and the full potential of $H$. colchicifolia as an antioxidant.

\section{Acknowledgments}

This research was supported by the Durban University of Technology and the National Research Foundation (NRF) of South Africa.

\section{References}

Ainsworth, E.A., Gillespie, K.M. 2007. Estimation of total phenolic content and other oxidation substrates in plant tissues using Folin-Ciocalteu reagent. Nature protocols, 2 , 875.

Akinrinde, A.S., Afolayan, A.J., Bradley, G. 2018. Phytochemical composition and antioxidant activities of Dianthus thunbergii hooper and Hypoxis argentea harv ex baker: Plants used for the management of diabetes mellitus in Eastern Cape, South Africa. Pharmacognosy magazine, 14, 195.

Amusan, O.O., Sukati, N.A., Shongwe, M.S. 2005. Some phytomedicines from Shiselweni region of Swaziland. Journal of Natural Remedies, 5, 19-25.

Badarinath, A., Rao, K.M., Chetty, C.M.S., Ramkanth, S., Rajan, T., Gnanaprakash, K. 2010. A review on in-vitro antioxidant methods: comparisions, correlations and considerations. International Journal of PharmTech Research, 2, 1276-1285.

Benzie, I.F., Strain, J.J. 1996. The ferric reducing ability of plasma (FRAP) as a measure of "antioxidant power": the FRAP assay. Analytical biochemistry, 239, 70-76.

Bourgaud, F., Gravot, A., Milesi, S., Gontier, E. 2001. Production of plant secondary metabolites: a historical perspective. Plant science, 161, 839-851.

Chavan, S.S., Damale, M.G., Shamkuwar, P.B., Pawar, D.P. 2013. Traditional medicinal plants for anticancer activity. International Journal of Current Pharmaceutical Research, 5, 50-54.

Choi, C.W., Kim, S.C., Hwang, S.S., Choi, B.K., Ahn, H.J., Lee, M.Y., Park, S.H., Kim, S.K. 2002. Antioxidant activity and free radical scavenging capacity between Korean medicinal plants and flavonoids by assay-guided comparison. Plant science, 163, 11611168 .

Güçlü, K., Altun, M., Özyürek, M., Karademir, S.E., Apak, R. 2006. Antioxidant capacity of fresh, sun-and sulphited-dried Malatya apricot (Prunus armeniaca) assayed by 
CUPRAC, ABTS/TEAC and folin methods. International journal of food science \& technology, 41, 76-85.

Hässig, A., Linag, W., Schwabl, H., Stampfli, K. 1999. Flavonoids and tannins: plant-based antioxidants with vitamin character. Medical Hypotheses, 52, 479-481.

Jooste, C.S. 2012. Brine shrimp lethality test and acetylcholine esterase inhibition studies on selected South African medicinal plants. Doctoral dissertation. University of the Western Cape.

Katerere, D.R. 2013. Hypoxis hemerocallidea (African potato): A Botanical Whose Time Has Come?. In African Natural Plant Products Volume II: Discoveries and Challenges in Chemistry, Health, and Nutrition (pp. 51-61). American Chemical Society.

Katerere, D., Eloff, J. 2008. Anti-bacterial and anti-oxidant activity of Hypoxis hemerocallidea (Hypoxidaceae): can leaves be substituted for corms as a conservation strategy? South African Journal of Botany, 74, 613-616.

Laher, F., Aremu, A., Van Staden, J., Finnie, J. 2013. Evaluating the effect of storage on the biological activity and chemical composition of three South African medicinal plants. South African journal of botany, 88, 414-418.

Laporta, O., Pérez-Fons, L., Mallavia, R., Caturla, N., Micol, V. 2007. Isolation, characterization and antioxidant capacity assessment of the bioactive compounds derived from Hypoxis rooperi corm extract (African potato). Food Chemistry, 101, 1425-1437.

Madikizela, B., Mcgaw, L. 2019. In vitro cytotoxicity, antioxidant and anti-inflammatory activities of Pittosporum viridiflorum Sims and Hypoxis colchicifolia Baker used traditionally against cancer in Eastern Cape, South Africa. South African Journal of Botany.

Meyer, B., Ferrigni, N., Putnam, J., Jacobsen, L., Nichols, D., Mclaughlin, J.L. 1982. Brine shrimp: a convenient general bioassay for active plant constituents. Planta medica, $\mathbf{4 5}$, 31-34.

Nair, S.S., Kavrekar, V., Mishra, A. 2013. In vitro studies on alpha amylase and alpha glucosidase inhibitory activities of selected plant extracts. European Journal of Experimental Biology, 3, 128-132.

Nair, V.D., Dairam, A., Agbonon, A., Arnason, J., Foster, B., Kanfer, I. 2007. Investigation of the antioxidant activity of African potato (Hypoxis hemerocallidea). Journal of Agricultural and Food Chemistry, 55, 1707-1711.

Ncube, B., Ndhlala, A.R., Okem, A., Van Staden, J. 2013. Hypoxis (Hypoxidaceae) in African traditional medicine. Journal of Ethnopharmacology, 150, 818-827.

Nsibande, B.E., Gustavsson, K.-E., Zhu, L.-H. 2018. Analysis of Health-Associated Phytochemical Compounds in Seven Hypoxis Species. American Journal of Plant Sciences, 9, 571.

Oboh, G. 2006. Antioxidant properties of some commonly consumed and underutilized tropical legumes. European Food Research and Technology, 224, 61-65.

Pandey, K.B., Rizvi, S.I. 2009. Plant polyphenols as dietary antioxidants in human health and disease. Oxidative Medicine and Cellular Longevity, 2, 270-278.

Phatak, R.S., Hendre, A.S. 2014. Total antioxidant capacity (TAC) of fresh leaves of Kalanchoe pinnata. Journal of Pharmacognosy and Phytochemistry, 2, 32-35. 
Ramulondi, M., De Wet, H., Van Vuuren, S. 2018. Toxicology of medicinal plants and combinations used in rural northern KwaZulu-Natal (South Africa) for the treatment of hypertension. Journal of Herbal Medicine, 100251.

Re, R., Pellegrini, N., Proteggente, A., Pannala, A., Yang, M., Rice-Evans, C. 1999. Antioxidant activity applying an improved ABTS radical cation decolorization assay. Free Radical Biology and Medicine, 26, 1231-1237.

Shahidi, F., Ambigaipalan, P. 2015. Phenolics and polyphenolics in foods, beverages and spices: Antioxidant activity and health effects-A review. Journal of functional foods, 18, 820-897.

Singh, Y. 2006. Hypoxis (Hypoxidaceae) in Africa: list of species and infraspecific names. Bothalia, 36, 13-23.

Singh, Y. 2007. Hypoxis (Hypoxidaceae) in southern Africa: taxonomic notes. South African Journal of Botany, 73, 360-365.

Sudha, G., Sangeetha, P., Indhu, S., Vadivukkarasi, S. 2011. Antioxidant activity of ripe pepino fruit (Solanum muricatum Aiton). International Journal of Pharmacy and Pharmaceutical Sciences 3, 257-261.

Surveswaran, S., Cai, Y.-Z., Corke, H., Sun, M. 2007. Systematic evaluation of natural phenolic antioxidants from 133 Indian medicinal plants. Food chemistry, 102, 938-953.

Tiwari, P., Kumar, B., Kaur, M., Kaur, G., Kaur, H. 2011. Phytochemical screening and extraction: a review. Internationale pharmaceutica sciencia, 1, 98-106.

Tusevski, O., Kostovska, A., Iloska, A., Trajkovska, L., Simic, S.G. 2014. Phenolic production and antioxidant properties of some Macedonian medicinal plants. Central European Journal of Biology, 9, 888-900.

Zengin, G., Guler, G.O., Aktumsek, A., Ceylan, R., Picot, C.M.N., Mahomoodally, M.F. 2015. Enzyme inhibitory properties, antioxidant activities, and phytochemical profile of three medicinal plants from Turkey. Advances in pharmacological sciences, 2015.

Zimudzi, C. 2014. African potato (Hypoxis Spp): Diversity and comparison of the phytochemical profiles and cytotoxicity evaluation of four Zimbabwean species. Journal of Applied Pharmaceutical Science, 4, 079-083. 